\title{
A IMPORTÂNCIA DA FORMAÇÃO CONTINUADA DO INSTRUTOR BOMBEIRO MILITAR NO BRASIL
}

Antônio Junio de OLIVEIRA ${ }^{1}$

Guaracy SILVA ${ }^{2}$

Sheldon William SILVA ${ }^{3}$

\begin{abstract}
${ }^{1}$ Especialista em Gestão Educacional pelo Centro Universitário do Sul de Minas - UNIS-MG. cepi@unis.edu.br ${ }^{2}$ Doutor em Educação pela Universidade Metodista de Piracicaba - UNIMEP-SP. guaracy@unis.edu.br

${ }^{3}$ Mestre em Administração pela Faculdade Pedro Leopoldo - FPL-MG. sheldonwilliamsilva@gmail.com
\end{abstract}

Recebido em: 10/10/2016 - Aprovado em: 14/05/2017 - Disponibilizado em: 01/07/2017

\begin{abstract}
RESUMO
O presente artigo tem por objetivo analisar a atual situação da formação continuada na prática pedagógica do instrutor Bombeiro Militar, bem como sua importância nas atividades de ensino no Corpo de Bombeiros Militar do Distrito Federal (CBMDF). As informações foram obtidas por meio de uma pesquisa bibliográfica e ainda uma análise das alternativas de formação ou especialização para o instrutor, existentes no CBMDF. Os resultados do trabalho de pesquisa revelam que não há um programa especifico e contínuo no CBMDF para o aperfeiçoamento das competências profissionais necessárias ao instrutor bombeiro militar. É preciso investir na capacitação do instrutor para que ele possa apreender a importância da aula dialogada, mesmo em um ambiente de aprendizagem baseado no ensino tradicional.

Palavras-chaves: Formação continuada, Instrutor, Prática pedagógica.
\end{abstract}

\section{ABSTRACT}

This paper aims to analyze the current situation of the continued training in the pedagogical practice of the Military Firefighter instructor, as well as its importance in teaching activities in the Military Fire Brigade of the Distrito Federal - Brazil (CBMDF). The information was obtained through a bibliographical research and an analysis of the alternatives of training or specialization for the instructor, existing in the CBMDF. The results of the research show that there is no specific and continuous program in the CBMDF for the improvement of the professional skills required by the military firefighter instructor. It is necessary to invest in the training of the instructors that he can apprehend the importance of the dialogued classroom, even in a learning environ men based nontraditional teaching.

Keywords: Continuing education, Instructor, Pedagogical practice.

\section{INTRODUÇÃO}

Este estudo tem como princípio a necessidade de qualificação profissional, que atualmente está explicita no dia a dia dos professores e também das outras categorias profissionais. Desta forma os cursos de capacitação de instrutores tornam-se um importante aliado na prática pedagógica do instrutor bombeiro militar, cuja responsabilidade está em formar o aluno que irá atender a comunidade nas diversas ocorrências do cotidiano da sociedade. É preciso que o instrutor acredite que é por meio dos seus conhecimentos técnicos e pedagógicos que o ensino se transformará em aprendizagem significativa para prática profissional do seu aluno.

Nesse trabalho busca-se identificar as características do instrutor militar, quais 
cursos estão disponíveis para sua formação e aperfeiçoamento das práticas pedagógicas para sua relevante atuação na formação profissional do bombeiro militar.

\section{ESTRUTURA ORGANIZACIONAL} DO CORPODE BOMBEIROS MILITAR DO DISTRITO FEDERAL (CBMDF)

O Corpo de Bombeiros Militar do Distrito Federal (CBMDF) foi instalado na Capital Federal, oriundo do Rio de Janeiro, em 1964. A estrutura organizacional é regida pela Lei n. ${ }^{\circ} 8.255$, de 20 de novembro de 1991, Lei de Organização Básica (LOB), alterada pela Lei Federal n. ${ }^{\circ} 12.086$, de 6 de novembro de 2009. Além destes normativos, a Constituição Federal descreve de maneira geral as atividades desenvolvidas pelos diversos Corpos de Bombeiros do Brasil, são elas:

Art. 42 Os membros das Polícias Militares e Corpos de Bombeiros Militares, instituições organizadas com base na hierarquia e disciplina, são militares dos Estados, do Distrito Federal e dos Territórios.

[...]Art. 144. A segurança pública, dever do Estado, direito e responsabilidade de todos, é exercida para a preservação da ordem pública e da incolumidade das pessoas e do patrimônio, através dos seguintes órgãos:

[...]V - polícias militares e corpos de bombeiros militares.

$[\ldots] \S 5^{\mathbf{o}}$ - às polícias militares cabem a polícia ostensiva e a preservação da ordem pública; aos corpos de bombeiros militares, além das atribuições definidas em lei, incumbe a execução de atividades de defesa civil.
$\S 6^{\circ}$ - As polícias militares e corpos de bombeiros militares, forças auxiliares e reserva do Exército, subordinam-se, juntamente com as polícias civis, aos Governadores dos Estados, do Distrito Federal e dos Territórios. (BRASIL, 1988).

O órgão responsável pelo ensino no CBMDF é a Diretoria de Ensino (DIREN), subordinada ao Departamento de Ensino, Pesquisa, Ciência e Tecnologia (DEPCT), conforme Figura 1.

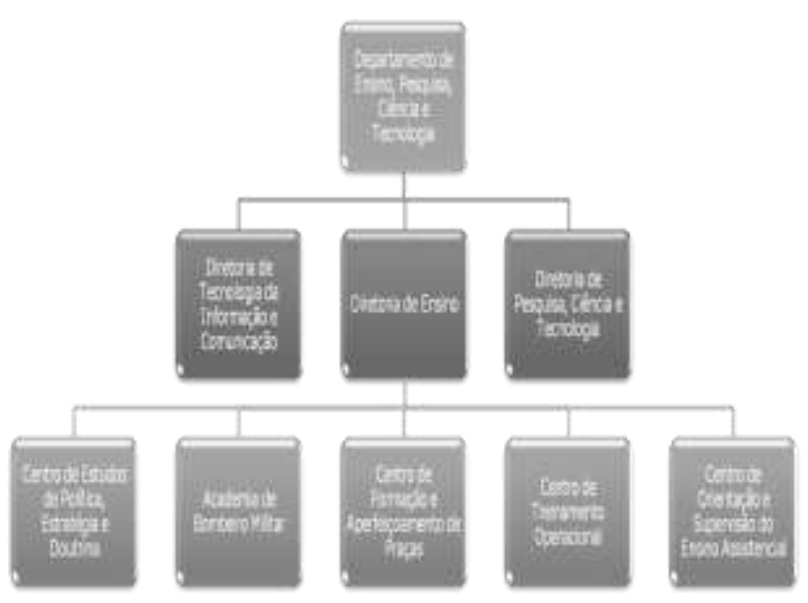

Figura 1: Estrutura organizacional do DEPCT Fonte: CBMDF (2010).

\section{LEGISLAÇÃO DE ENSINO APLICADA AO CBMDF}

A Lei de Diretrizes e Bases da Educação (LDB), Lei n. ${ }^{\circ}$ 9.394, de 20 de dezembro de 1996, traz importante dispositivo, o artigo 83, que estabelece o Ensino Militar como sendo regulado em lei específica, admitida a equivalência de estudos, de acordo com as normas fixadas pelos sistemas de ensino de cada corporação.

Diante destas normativas, temos que o Ensino no CBMDF possui normas internas que orientam a formação e norteiam as ações, 
estabelecendo os fundamentos e princípios filosóficos do ensino bombeiro militar.

A educação profissional do CBMDF é a área especificamente vocacionada para conduzir os processos de ensinoaprendizagem corporativos, carecendo, atualmente, de um maior apoio dos gestores para efetivar-se como a mola propulsora do desenvolvimento institucional e manutenção do status quo corporativo.

Neste contexto a Portaria do CBMDF $\mathrm{n}^{\circ} 28$, de 20 de outubro 2010, aprovou a Política de Ensino e a Diretriz Geral do Sistema de Ensino Bombeiro Militar (SEBM) do CBMDF. Tais normas foram essenciais para a unificação da legislação do SEBM que antes estava dispersa em vários documentos, sem uma padronização da linguagem filosófica pedagógica e dos procedimentos administrativos necessários para que o ensino pudesse promover a profissionalização bombeiro militar nos diferentes contextos e cumprindo com a missão de salvar e proteger vidas, patrimônio e o meio ambiente.

No mesmo ano foi aprovado o Regulamento dos Preceitos Comuns aos Estabelecimentos de Ensino (RPCEE), que ministram cursos ou estágios do CBMDF, por meio da Portaria CBMDF n ${ }^{\circ} 29$, de 25 de novembro de 2010.

Este RPCEE trouxe as funções e a definição atual do conceito de instrutor, sendo qualquer militar do CBMDF, independente da sua função ou cargo, tendo como premissa a qualificação profissional no assunto. Diferente das normas anteriores, que limitavam a determinados segmentos da Corporação. Esta normativa progride e aponta uma novidade, um avanço no ensino bombeiro militar, pois mesmo sendo o responsável pelo conteúdo a ser ministrado nas aulas, alguns bombeiros somente poderiam ser nomeados como "monitores", isto é, um auxiliar do instrutor.

Agora, sendo o instrutor reconhecido como parte integrante do processo de ensino aprendizagem, neste momento torna-se ainda mais relevante o aperfeiçoamento continuado dos seus conhecimentos e da formação profissional, o estímulo e o aprimoramento das metodologias e processos de ensino para a construção do conteúdo curricular.

Como bem observa Mizukami (2002), todos os profissionais que trabalham na área de educação necessitam de algumas bases de conhecimento, sendo os conhecimentos científicos dentro da área de atuação, e nem menos importante os conhecimentos e competências da profissão relacionados à docência. Vale frisar também, que professor é o responsável por propor os instrumentos para que ocorra a construção do conhecimento, e a base de conhecimentos pela experiência onde ele tende a distinguir as maneiras adequadas para a sua atuação dentro da sala de aula.

Para realizar a formação e o preparo, o CBMDF possui a premissa da qualificação como visão de futuro, indicada em seu Plano Estratégico 2011-2016 do CBMDF, tornado 
público pelo Boletim Geral (BG) n. ${ }^{\circ} 224$, de 8 de dezembro de 2010, página 2, a saber: "Ser referência para a sociedade pela excelência dos serviços prestados, por meio da qualificação dos seus integrantes, da gestão estratégica da Instituição, do constante reequipamento e da inovação tecnológica". Para tanto possui normas internas que regulamentam o ensino e a instrução.

\subsection{Características do SEBM}

O SEBM tem características próprias e conectadas ao desempenho das funções bombeiro militar na promoção ao desenvolvimento de competências que atentam para a formação científica e humanística necessárias para a educação profissional, entre elas temos:

Responsabilidade
construir e trabalhar o conhecimento
fundamentado em uma concepção
metodológica na qual teorias e práticas
educativas estão fomentadas em ações
técnicas profissionais embasadas em análises
de possibilidades que ocorrem e desafiam o
cotidiano profissional;
Responsabilidade
comprometimento sócio global: construção
do saber e nas diferentes atribuições e
atividades de execução e trabalhos, tendo
como proposta educacional seu
desenvolvimento por meio dos níveis de

graduação, pós-graduação, pesquisa e extensão;

Promoção de um ensino de qualidade: preocupação em alcançar os avanços da ciência e os processos e procedimentos que envolvem e enriquecem a integração pedagógica na sua tradução do ensino e da aprendizagem;

Concepção pedagógica das competências: saber ser, saber pensar e saber agir: provocado pelos princípios da pedagogia da integração, na realização e articulação com as mais diversas áreas do saber e também na valorização da doutrina militar e da ética profissional o SEBM se organiza e se faz estabelecer quando da proposta de articulação de um trabalho educacional voltado para a qualificação profissional.

Fortalecimento e aperfeiçoamento dos processos de desempenho de todo o sistema de ensino: constante reconstrução e redefinição de linhas de pensamento e ações para as práticas pedagógicas, fundamentado em um ensino autônomo e de características próprias.

\section{ASPECTOS METODOLÓGICOS E RESULTADOS}

Como a primeira alternativa de capacitação de instrutores, temos o Curso de Métodos e Técnicas de Ensino Bombeiro Militar (CMTE BM) aprovado em 2012, por meio da Portaria do CBMDF de $n^{\circ} 57$, de 31 de outubro de 2012. Este curso tem como 
propósito capacitar os instrutores das diversas áreas de atuação do bombeiro militar nas ações que são atribuídas constitucionalmente, de forma que os instrutores possam, a partir das suas práticas como docentes, contribuir com o processo de formação profissional bombeiro militar, baseado no ensino por competências.

Nesta perspectiva podemos afirmar, segundo as contribuições de (PORTILHO, 2011), que o docente ao se conhecer cada vez um pouco mais, adquire a habilidade de analisar as exigências das tarefas e relacionálas com a realidade que se apresenta. Pode refletir sobre a informação, averiguar o objetivo da atividade que deve cumprir, observar o que há de novo e familiar e detectar os níveis de dificuldade, tornando-se assim autônoma em suas aprendizagens.

Para o conhecimento das ações desenvolvidas durante as capacitações, é importante frisar as abordagens pesquisadas sobre ensino e instrução, para isso Libâneo destaca:

A instrução refere-se à formação intelectual, formação e desenvolvimento das capacidades cognoscitivas mediante $\mathrm{o}$ domínio de certo nível de conhecimentos sistematizados. O ensino corresponde a ações, meios e condições para a realização da instrução; contém, pois, a instrução (LIBÂNEO, 1994, p.23).

Nessa abordagem, o objetivo é "proporcionar aos alunos os meios para que assimilem ativamente os conhecimentos" e ainda fomentar a "natureza do trabalho docente é a mediação da relação cognoscitiva entre o aluno e as matérias de ensino" (LIBÂNEO, 1994, p. 54).

O aperfeiçoamento contínuo dos docentes produz inúmeros resultados positivos para o ensino civil e também para o ensino bombeiro militar. Nesse aspecto, é correto afirmar que "É pensando criticamente a prática de hoje ou de ontem é que pode melhorar a próxima prática" (FREIRE, 1996, p. 43). A volta do "professor" para a sala de aula quebra um ciclo vicioso em que o militar se encontra, tratando-se apenas como instrutor com os aprendizados que teve durante sua formação ou especialização.

Ao ter contato com os outros instrutores durante o CMTE BM o militar encontra outras técnicas que podem ser utilizadas em sala de aula, e ainda tem a oportunidade de conhecer as novas abordagens didáticas para que possa aperfeiçoar sua conduta em sala de aula, e desta forma o "desenvolvimento de recursos humanos tem uma única e identificada função: refere-se à promoção de aprendizagem para empregados (ou não), visando ajudar a organização no alcance de seus objetivos" (BORGES; ANDRADE; MOURÃO, 2006, p. 141-142). Vale destacar também que o CMTE BM se propõe a resgatar os valores e a cultura bombeiro militar, as vezes esquecidos durante as instruções. 
É preciso compreender que a prática docente, conforme proposta curricular do CMTE BM disposta na Tabela - 1, na educação profissional vive um constante exercício, na medida em que ele aplica suas vivencias de sala de aula e contribui com suas estratégias típicas de docência (TARDIF; LESSARD, 2009).

Tabela 1 - Malha curricular do CMTE BM

\begin{tabular}{lc}
\hline DISCIPLINAS CURRICULARES & CARGA HORÁRIA \\
\hline O Sistema de Ensino do CBMDF & $2 \mathrm{~h} / \mathrm{a}$ \\
Didática do Ensino BM & $48 \mathrm{~h} / \mathrm{a}$ \\
Planejamento Educacional & $12 \mathrm{~h} / \mathrm{a}$ \\
Recursos Multissensoriais & $6 \mathrm{~h} / \mathrm{a}$ \\
Métodos de Avaliação & $12 \mathrm{~h} / \mathrm{a}$ \\
Trabalho Prévio & $6 \mathrm{~h} / \mathrm{a}$ \\
Coordenação & $4 \mathrm{~h} / \mathrm{a}$ \\
Total & $\mathbf{9 0}$ \\
\hline Fonte: CBMDF - Portaria 57, de 31 de outubro de 2012.
\end{tabular}

$\mathrm{O}$ instrutor/professor formado pelo CMTE BM terá condições de atuar em aulas e em instruções que exijam a prática pedagógica militar; uma vez que o ensino do CBMDF está caracterizado na modalidade de cursos profissionalizantes pela sua caracterização própria da profissão militar, contemplado pelo Art.83, da Lei de Diretrizes e Bases da Educação Nacional Lei n. ${ }^{\circ}$ 9394/96.

Neste sentido, o curso formou no período de 2012 a 2015 uma quantidade de 192 (cento e noventa e dois) militares dos diversos setores do CBMDF, conforme Tabela 2, construindo assim uma política de valorização e aperfeiçoamento dos profissionais que são instituídos como docentes e responsáveis pela doutrina bombeiro militar durante a formação e aperfeiçoamento dos alunos.

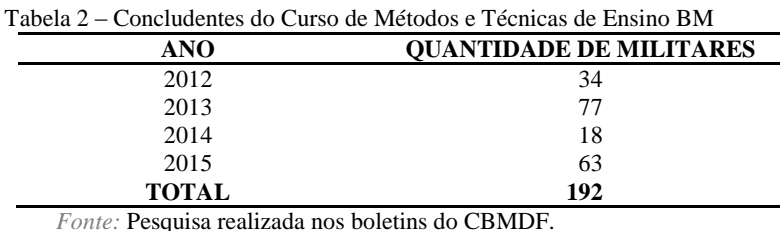

Dentro de outra perspectiva, o Centro de Treinamento Operacional, órgão subordinado a DIREN, que tem a incumbência de formar e atualizar instrutores de atividades operacionais da Corporação, conforme preconiza o Item I, do Art. 10, do Decreto $n^{\circ} 31.817$ de 21 de Junho de 2010, procura atender a demanda de docentes da área de ensino e da área operacional. Para suprir esta demanda foi aprovada a criação do Curso de Instrutor de Combate a Incêndio Urbano (CICOI).

Diferente da proposta do CMTE BM, este curso visa à formação do instrutor na área de combate a incêndio e salvamento. A atividade de Instrutor de Combate a Incêndio Urbano é muitas vezes exercida por Bombeiros Militares que não tem a formação adequada para desenvolver a docência.

Em termos práticos, o CICOI tem por objetivo capacitar o Bombeiro Militar a ministrar a disciplina de combate a incêndio urbano nos diferentes contextos encontrados no CBMDF de forma a difundir e fortalecer os conhecimentos da área, permitindo a disseminação da doutrina de combate a incêndio urbano do CBMDF por meio da multiplicação do conhecimento adquirido, o desenvolvimento e o aprimoramento das habilidades necessárias à realização das 
ações de combate a incêndio urbano, assim como o ensino destas habilidades nos diversos cursos da Corporação.

Além de propiciar os conhecimentos oriundos ao combate ao incêndio, o CICOI busca preparar o instrutor para ministrar aulas, com o domínio de conteúdo técnicoespecializado e a construção o conhecimento essencial.

A aprovação do CICOI foi publicada por meio da Portaria CBMDF de $\mathrm{n}^{\circ} 100$, de 29 de dezembro de 2011, contando com a quantidade de 74 (setenta e quatro) militares formados desde 2012, conforme Tabela 3.

\begin{tabular}{cc} 
Tabela 3 - Curso de Instrutor de Combate a Incêndio Urbano \\
\hline ANO & QUANTIDADE DE MILITARES \\
\hline 2012 & 31 \\
2013 & 26 \\
2014 & 17 \\
2015 & 0 \\
TOTAL & $\mathbf{7 4}$ \\
\hline
\end{tabular}

O CICOI foi elaborado, conforme é possível verificar em sua Malha Curricular Tabela 4, para formar uma base de conhecimentos sobre o trabalho de combate a incêndio, com uma linguagem padronizada que favorece as ações durante as ocorrências de incêndio.
Tabela 4 - Malha curricular do CICOI

\begin{tabular}{lc}
\multicolumn{1}{c}{ DISCIPLINAS CURRICULARES } & CARGA \\
& HORÁRI \\
& A \\
\hline Métodos Pedagógicos nas Instruções de Combate a Incêndio & $8 \mathrm{~h} / \mathrm{a}$ \\
Elaboração de Planos de Aula & $4 \mathrm{~h} / \mathrm{a}$ \\
Recursos didáticos e Multimídia & $4 \mathrm{~h} / \mathrm{a}$ \\
Métodos de Avaliação & $8 \mathrm{~h} / \mathrm{a}$ \\
Teoria do fogo & $8 \mathrm{~h} / \mathrm{a}$ \\
Dinâmica do Incêndio & $4 \mathrm{~h} / \mathrm{a}$ \\
Comportamentos extremos do fogo & $8 \mathrm{~h} / \mathrm{a}$ \\
Equipamento de Proteção Individual (EPI) de Combate a Incêndio & $16 \mathrm{~h} / \mathrm{a}$ \\
Urbano & \\
Armação de Mangueiras & $12 \mathrm{~h} / \mathrm{a}$ \\
Técnicas de Combate a Incêndio Urbano & $16 \mathrm{~h} / \mathrm{a}$ \\
Utilização de escada prolongável & $6 \mathrm{~h} / \mathrm{a}$ \\
Treinamento em simulador de incêndio do tipo contêiner & $16 \mathrm{~h} / \mathrm{a}$ \\
Técnicas de Busca e Salvamento nos incêndios & $12 \mathrm{~h} / \mathrm{a}$ \\
Prevenção e combate a princípio de incêndio para público civil & $12 \mathrm{~h} / \mathrm{a}$ \\
Utilização e operação de viaturas de combate a incêndio urbano & $16 \mathrm{~h} / \mathrm{a}$ \\
Preparação para o socorro & $4 \mathrm{~h} / \mathrm{a}$ \\
Fundamentos de estratégia e tática de combate a incêndio urbano & $6 \mathrm{~h} / \mathrm{a}$ \\
Ações Estratégicas Táticas de combate a incêndio e salvamento & $10 \mathrm{~h} / \mathrm{a}$ \\
Orientações sobre simulados de combate a incêndio urbano & $2 \mathrm{~h} / \mathrm{a}$ \\
Visitas técnicas a edificações & $6 \mathrm{~h} / \mathrm{a}$ \\
Simulados & $22 \mathrm{~h} / \mathrm{a}$ \\
Pratica de Ensino & $160 \mathrm{~h} / \mathrm{a}$ \\
TOTAL & $\mathbf{3 6 0} \mathrm{h} / \mathbf{a}$ \\
\hline Fonte: CBMDF - Portaria 100, de 29 de dezembro de 2011. & \\
&
\end{tabular}

\section{CONSIDERAÇÕES FINAIS}

Neste momento percebe-se que os dois cursos relacionados acima buscam pelo aperfeiçoamento e formação de instrutores, o que está em consonância com as orientações e diretrizes do Sistema de Ensino e tem como pressuposto básico garantir aos seus profissionais meios para que esses busquem a atualização e a contínua construção do saber, uma vez que a humanidade tem evidenciado processos rápidos de mudanças de paradigmas e consequentemente quebras de consensos muitas vezes tidos como únicos e verdadeiros.

Conclui-se que é preciso ir além, renovar conhecimentos a partir da construção de novas concepções educacionais necessárias ao desenvolvimento das práticas 
pedagógicas, dentro de um programa institucional de capacitação de instrutores, organizado e de acordo com a área de conhecimento de cada instrutor.

Deste modo, é de extrema importância a formação continuada dos instrutores, pois o que percebemos é que o aperfeiçoamento do capital humano é um diferencial nas organizações modernas, sendo que na Administração pública e principalmente no CBMDF, pois trabalhamos com o bem maior do ser humano e por isso torna-se fundamental para o preparo correto dos instrutores auxiliando-os ao desenvolvimento de práticas pedagógicas eficazes e condizente com o contexto atual

Este trabalho requer um estudo maior que possa analisar quais são as áreas do conhecimento dentro do SEBM carentes de instrutores capacitados para que possamos conhecer melhor as demandas e planejar ações para este grupo.

\section{REFERÊNCIAS BIBLIOGRÁFICAS}

BORGES, Jairo E; ANDRADE, Gardênia da Silva Abbad; MOURÃO, Luciana. Treinamento, desenvolvimento e educação em organização e trabalho: fundamentos para gestão de pessoas. Porto Alegre: Artmed, 2006.

BRASIL. Constituição Federal (1988). Constituição da República Federativa do Brasil. Brasília, DF: Senado Federal: Centro Gráfico, 1988

.Lei n. ${ }^{\circ} 9.394$, de 20 de dezembro de 1996. Estabelece as diretrizes e bases da educação nacional. Diário Oficial da
República Federativa do Brasil, Poder Executivo, Brasília, DF, 23 dez. 1996.

Lei n. ${ }^{\circ} 12.086$, de 06 de novembro de 2009. Dispõe sobre os militares da Polícia Militar do Distrito Federal e do Corpo de Bombeiros Militar do Distrito Federal; altera as Leis [...] e dá outras providências.

Lei $n^{\circ} 8.255$, de 20 de novembro de 1991. Dispõe sobre a organização básica do Corpo de Bombeiros Militar do Distrito Federal e dá outras providências. Diário Oficial da República Federativa do Brasil, Poder Executivo, Brasília, DF, 21 nov. 1991.

CBMDF. Corpo de Bombeiros Militar do Distrito Federal. Portaria n. ${ }^{\circ} 28$, de 20 de outubro de 2010. Diretriz geral do sistema de ensino bombeiro militar. Boletim Geral n. ${ }^{\circ}$ 195, de 21 de out. de 2010.

Plano Estratégico 2011-2016.

Publicado no Boletim Geral de n. ${ }^{\circ} 224$, de 8 de dezembro de 2010.

Portaria n. ${ }^{\circ} 29$, de 25 de novembro de 2010. Regulamenta os preceitos comuns aos Estabelecimentos de Ensino que ministram cursos ou estágios do CBMDF. Boletim Geral n. ${ }^{\circ}$ 218, de 26 de novembro de 2010.

Portaria n. ${ }^{\circ} 100$, de 29 de dezembro de 2011. Aprova a criação do Curso de Métodos e Técnicas de Ensino Bombeiro Militar (CMTE BM) e dá outras providências. Boletim Geral n. ${ }^{\circ} 245$, de 30 de dezembro de 2011.

Portaria n. ${ }^{\circ}$ 57, de 31 de outubro de 2012. Aprova a criação do Curso de Métodos e Técnicas de Ensino Bombeiro Militar (CMTE BM) e dá outras providências. Boletim Geral n. ${ }^{\circ}$ 207, de 5 de novembro de 2012.

DISTRITO FEDERAL. Decreto Distrital n. ${ }^{\circ}$ 31.817 de 29 de abril de 2010. Regulamenta o inciso I do art. 10-B da Lei $n^{\circ} 8.255$, de 20 de novembro de 1991, no que se refere à organização básica do Corpo de Bombeiros Militar do Distrito Federal. 
FREIRE, Paulo. Pedagogia da autonomia:

Saberes necessários a prática educativa. São

Paulo: Paz e Terra, 1996.

LIBÂNEO, J.C. Didática. São Paulo: Cortez, 1994.

MIZUKAMI, Maria da Graça Nicoletti.

Formação de professores, práticas

pedagógicas e escola. São Carlos: Ed.

UFSCar, 2002.

PORTILHO, E.M.L. Como se aprende?

Estratégias, estilos e metacognição. Rio de janeiro: WAK, 2011.

TARDIF, M.; LESSARD, C. O trabalho docente: elementos para uma teoria da docência como profissão de interações humanas. Petrópolis, RJ: Vozes, 2009. 